\title{
REFLEXÕES SOBRE SER PROFESSOR DE GEOGRAFIA: O QUE DIZ
}

\author{
A SALA DE AULA \\ Genilson Oliveira Costa Silva, Universidade Federal de Campina Grande (UFCG) \\ genilsoncostaesilva2017.1@gmail.com \\ Cícera Cecília Esmeraldo Alves, Universidade Federal de Campina Grande (UFCG) \\ ceciliaesmeraldo@gmail.com
}

\begin{abstract}
RESUMO
O trabalho busca desenvolver uma discussão acerca das reflexões feitas sobre a formação do futuro professor de geografia, tendo como base os Estágios Supervisionados, sendo a vivência nas dependências escolares de fundamental importância para as análises que seguem. Os estágios ocorreram nas escolas E.M.E.I.F. Cecília Estolano Meireles, do $1^{\circ}$ ao $3^{\circ}$ e na escola E.E.E.F.M. Monsenhor Constantino Vieira, o $4^{\circ}$ estágio, que respectivamente foram serviram para a construção e aprimoramento dos potenciais já existentes enquanto graduando. Portanto, as discussões feitas na academia durante o curso, possibilitaram realizar uma análise referente ao processo de ensino e aprendizagem, buscando entender o que é ser um professor, como também construindo uma ponte conceitual do que é esse espaço para o futuro educador. Quanto ao método de pesquisa definido, baseou-se no de pesquisa-ação, entendendo que o conhecer para agir é de fundamental importância na construção do conhecimento e valorização da própria pesquisa acadêmica, considerando a vivência como suporte no que se refere á práxis. E a partir da contribuição de alguns teóricos da área, foi possível trazer uma discussão que corrobora-se na construção do conhecimento coletivo, objetivando também compreender como o Estágio Supervisionado pode ser um componente articulador da relação entre teoria e prática.
\end{abstract}

PALAVRAS CHAVES: Estágio Supervisionado, Ensino de Geografia, Metodologia.

\section{REFLEXIONES SOBRE SER UN PROFESOR DE GEOGRAFÍA: LO QUE DICE EL AULA}

El trabajo busca desarrollar una discusión sobre las reflexiones realizadas sobre la formación del futuro profesor de geografía, basado en las etapas supervisadas, siendo la experiencia en las dependencias escolares de importancia fundamental para los análisis que siguen. Las etapas ocurrieron en las escuelas E.M.E.I.F. Cecilia Estolano Meireles, del 1 al 3 y en la Escola E.E.E.F.M. Monseñor Constantino Vieira, la 4ta etapa, que fueron servidas respectivamente para la construcción y la mejora de los potenciales existentes mientras que se gradúan. Por lo tanto, las discusiones realizadas en la Academia durante el curso, permitieron realizar un análisis del proceso de enseñanza y aprendizaje, buscando entender lo que es ser un maestro, como también la construcción de un puente conceptual de lo que es este espacio para el futuro educador. En cuanto al método de investigación definido, se basó en la investigación-acción, 
entendiendo que el conocimiento a actuar es de fundamental importancia en la construcción de la conciencia y la apreciación de la investigación académica misma, considerando la experiencia como un apoyo a la praxis. Y a partir de la contribución de algunos teóricos de la zona, fue posible aportar un debate que corroborara la construcción del conocimiento colectivo, con el objetivo de comprender también cómo la etapa supervisada puede ser un componente articulador de la relación entre teoría y práctica.

PALABRAS CLAVE: Pasantía Supervisada, Enseñanza de Geografía, Profesor, Metodología.

\section{INTRODUÇÃO}

No mundo moderno, palco de grandes transformações, tudo está em processo contínuo e dinâmico, que vai desde as próprias leis naturais as relações sociais entre os sujeitos. Desta forma, a escola como instituição responsável pela formação de indivíduos para/na sociedade tem o dever de acompanhar os distintos modelos sociais estabelecidos no espaço-tempo, ou seja, a escola tem que atender as expectativas do social, respondendo assim às necessidades que a priori não existiam e, ainda fomentando discussões que até então eram desconsideradas, ou até que não pertencia ao espaço escolar. O presente ensaio busca levantar questionamentos referentes ao novo e, talvez não tão novo assim, papel da escola, como também do professor, no processo de formação do alunado, como principalmente na formação do próprio educador, a partir das observações realizadas enquanto estagiário nos quatro distintos períodos.

Baseando assim nas discussões realizadas na academia durante toda trajetória no curso de Licenciatura em Geografia, na Universidade Federal de Campina Grande, no Centro de Formação de Professores e nas escolas E.M.E.I.F. Cecília Estolano Meireles, do $1^{\circ}$ ao $3^{\circ}$ e na escola E. E. E. F. M. Monsenhor Constantino Vieira, foi possível desenvolver uma análise referente ao processo de ensino e aprendizagem, buscando entender o que é ser um professor, como também construindo uma ponte conceitual do que é esse espaço para o futuro educador em especial, a partir do estágio supervisionado. Entendendo assim a importância do domínio de metodologias eficazes no processo construtivo do saber, dentro e fora a sala de aula.

Para tal embasamento, buscou-se em autores como Pimenta e Lima (2004), Buriolla (2001) Castrogiovanni (2007) e outras definições que ajudem a entender a dinamicidade da sala de aula, como também do estágio e da própria escola como um 
todo, corroborando dessa forma para o enriquecimento das abordagens que se seguem. E a partir dessas leituras foi possível aplicar metodologias capazes de aproximar o conhecimento científico discutido na academia com a realidade da sala de aula.

De maneira geral, o estágio Supervisionado dentro do Currículo de um licenciado, neste caso de Geografia, tem como finalidade proporcionar uma oportunidade de reflexão por parte daqueles que o exercem. Pois é nesse momento da formação que o sujeito irá realizar seus primeiros confrontos entre a teoria e a prática, ampliando assim seu universo a partir da vivência. Contudo, o estágio pode ser visto como momentos ímpares na formação de um educador e quando levado a sério, proporciona uma formação completa e satisfatória.

\section{REFLEXÕES ACERCA DO ESTÁGIO SUPERVISIONADO: IMPORTÂNCIAS E DESAFIOS}

Refletir sobre esta temática é uma tarefa bastante difícil, porém, necessária, mesmo havendo muitos estudos direcionados a esse objeto. O que na verdade torna ainda mais complexa essa atividade de reflexão, pois se está havendo um direcionamento de olhares para esse fim, não obstante é por apresentar-se com necessidades de análises e aprimoramento.

É bastante sabido que, o ensino de geografia vem passando por uma série de mudanças, que perpassa da forma como é visto a teoria como também sua prática. Para tanto, diante as reflexões acerca das práticas sobre formação docente, tendo em vista o atual papel da escola na sociedade em virtude das transformações sócio-espaciais que a sociedade vem passando, perpassando da escala regional a global, Castrogiovanni diz que:

O desafio a que se propõem esses professores é pensar sua própria prática e exercitar sua formação docente para além do compromisso funcional a que se habilitam com a titulação em Licenciado em Geografia. E mostrar que é possível fazer diferente da monotonia que se implantou nas escolas de um modo geral e da geografia particularmente. (CASTROGIOVANNI, 2007:8). 
O autor coloca com precisão o desafio que é pensar a própria prática docente, possibilitando ao mesmo, ferramentas para um aperfeiçoamento enquanto profissional formado e já atuante, embora que em constante processo de formação continuada. Pensando claro na perspectiva de qualidade, como bem aponta Oliveira (2009, p. 11), em sua obra "Sentidos da Geografia Escolar", afirmando que:

... quando se fala em educação de qualidade - e não meramente de quantidade (que também deve existir à medida que essa escola deve ser para todos e não somente para uma elite) - está se pensando não em termos de conteúdo ou mesmo de ideologia, mas sim numa escola que aprimore e expanda nos alunos determinadas competências, habilidades ou múltiplas inteligências. (OLIVEIRA, 2009 p. 11).

Reforçando a discussão Buriolla (2001), ainda acrescenta sobre a atividade de estágio que:

O estágio é concebido como um campo de treinamento, um espaço de aprendizagem do fazer concreto, onde um leque de situações, de atividades de aprendizagem profissional, que se manifesta para o estagiário, tendo em vista sua formação. (BURIOLLA, 2001:13)

Por tanto, é perceptível que no estágio o indivíduo está em contato direto com a realidade "real" do espaço, mas também imerso na própria subjetividade, fazendo com que esse momento da formação do futuro professor possa lhe proporcionar diferentes maneiras de análises referentes a distintas situações que são manifestadas neste período de contato direto com o espaço escolar, com a sala de aula. Todos os estágios tiveram sua importância, que vai desde, a saber, como conhecer os espaços físicos, como o corpo docente (incluindo as pessoas que trabalham em setores como na limpeza ou em outros que possibilitam o funcionamento da instituição). Logo, esse reconhecimento possibilitará um melhor direcionamento nas atividades que assim planejar desenvolver.

O estágio supervisionado, portanto, é um momento de fundamental importância no processo de formação do profissional. Visto isso, Pimenta e Lima (2004), acreditam que é o eixo central da formação de professores, pois é através dele que o profissional conhece os aspectos indispensáveis para a formação da construção da identidade e dos saberes do dia-a-dia.

Nesse sentido, o estágio acaba por ser um momento ímpar na formação profissional. Nele será possível apreciar os primeiros contatos com a sala de aula agora 
não mais como aluno. Sendo importante destacar que é nesse momento que muitos licenciandos podem optar por dois caminhos, um seria abandonar a profissão por não haver identificação com a área, ou simplesmente identificar- se pela atividade profissional, que nada mais é que uma arte.

Ainda quanto à importância do estágio, é de muita relevância que o mesmo seja visto não apenas como uma atividade que tem que ser cumprida no âmbito da academia, mas que servirá de subsídios para a formação do futuro profissional em processo de aprimoramento. E como desafio encontra-se a tão discutida e sonhada práxis. Visto isso Guerra (1995), afirma que o Estágio Supervisionado consiste na relação teoria e prática, tendo em vista uma busca constante do contato real para com o espaço escolar, para uma elaboração conjunta do programa de trabalho na formação do educador.

E como reforço a essa reflexão Silva (2003, p. 17), informa que o estágio deve ser concebido como um espaço de problematização das ciências gerais e específicas, em que a práxis educativa é tomada como objeto de estudo e de compreensão da transição dos conhecimentos. Portanto, o mesmo aponta que um dos grandes desafios com o qual o aluno de um curso de licenciatura tem é lidar com a união da prática e da teoria. E caso esse problema não seja solucionado ou pelo menos reduzido durante a vida acadêmica do educando, essa dificuldade se refletirá na sua prática como futuro professor.

Sendo aqui inquestionável a importância da relação feita entre a teoria e prática, como também é muito visto o discurso limpo e puramente acadêmico, que vem ocorrendo há muito tempo em meio aos que se dizem "Autoridades na Área da Educação". Muitas vezes quando os estagiários chegam às escolas vêem que o discurso arrumadinho visto na academia, fica barrado nas próprias limitações que a escola como um todo apresenta, sejam elas estruturais ou no que se refere aos recursos humanos.

De acordo com Nóvoa (2009), aponta em um dos seus trabalhos que o próprio educador vem com o tempo perdendo espaço para segundos personagens que nunca sequer tiveram contato com a sala de aula em suas mais variadas dimensões (culturais, raciais e étnicas). $\mathrm{O}$ mesmo deixa bem claro que não se pode preencher a lacuna entre os discursos e as práticas se não houver de fato um campo autônomo, que possibilite abertura ao profissional. 
Sem muita dificuldade, pode ser percebido que há um contundente e cansativo discurso, se não apenas teórico, mas ideológico que se enraizou no cerne de muitos sujeitos envolvidos com o processo de ensino e aprendizagem. Percebe-se que há uma forte utilização de conceitos e linguagens que tratam sobre problemas da profissão docente.

E a partir dessa ideia, ouso em aderir ao termo "Crítico reprodutivista educacional", onde verifica-se que há uma repetição desnecessária, já que não há aplicação dessas abordagens. Pois sabe-se onde está o problema, mas as análises realizadas não têm a competência de ultrapassar as barreiras que dividem a teoria das práticas educativas. Acabando por existir um discurso redundante e palavroso sem haver a ação esperada, como bem coloca Nóvoa (2009).

Assim os estágios realizados nas escolas serviram para perceber em primeiro momento como o espaço da sala de aula é dinâmico, operando-se a cada momento. $\mathrm{O}$ $1^{\circ}, 2^{\circ}$ e $3^{\circ}$ Estágios se deram na primeira escola, na qual elucidado pelas discussões teórico-metodológicas da academia pôde-se apropriar-se de muitas experiências que com certeza contribuíram na formação como futuro educador.

E não diferente dos anteriores, esse último momento de estágio, proporcionado na segunda escola fez perceber o quanto é preciso estar preparado para desafios diários. Seja ao preparar aulas ou, ao ministrá-las. Como também a importância do uso de recursos que motivem os alunos a participarem e apreender o que está sendo colocado, de maneira construtiva e crítica, entendo que o professor estagiário quanto o professor regente estão direcionados a indicar os melhores caminhos para a elucidação dos questionamentos.

E, ainda nesse momento, destacaria a utilização de meios tecnológicos na aplicação das aulas. É notória a dificuldade que muitos professores apresentam no manejo de certos equipamentos de informática, como também o próprio estagiário, sendo assim importante conhecer bem os equipamentos disponíveis em sala de aula para que se possa realizar um bom trabalho.

Enfim, deve-se responder aos anseios da atual sociedade, sempre buscando novas ferramentas que dinamizam as aulas, que muitas vezes são consideradas chatas e com pouca produtividade. 


\section{AULA DE GEOGRAFIA: COMO SER O PROFESSOR?}

A aula é mais que um ato de amor, é uma ação filosófica de amor e ódio entre os sujeitos e as reflexões acerca do melhor caminho a ser trilhado, rumo à construção dos diferentes e dinâmicos saberes. A aula de Geografia deve por excelência privilegiar a prática da reflexão seguida de ações, sendo assim pautado pelo método pesquisa-ação. Fazendo com que o futuro professor possa, conforme nos indica Saviani (2007), transpor do senso comum à consciência filosófica.

Sendo no palco da sala de aula que se modificam os laços subjetivos criados pela sociedade em vigor. É nele que se configura o novo sobreposto no velho, em perfeita desarmonia, que aos poucos entra e possibilita aos sujeitos à reconstrução dos diferentes saberes.

Os estágios realizados possibilitaram compreender como funcionam as relações internas da escola não mais pela ótica de apenas estudantes, mas agora de um educador em processo de formação, tendo sido de extrema importância já que se almeja ser um futuro presente professor.

Tendo em vista o título deste sub-tema, muito anda sendo questionado o como deve ser o professor nos dias atuais. Será que o mesmo ainda desempenha as mesmas funções que a priori eram responsáveis?, ou com as contínuas mudanças esse profissional também sofreu modificações?

Já foi discutido que a escola passou por processos de mudanças em virtude do próprio avanço e dinamismo das relações sociais. O professor não diferente, também teve de acompanhar essa dinamicidade, primeiro porque a escola é tão parte do professor quanto ele dela.

$\mathrm{O}$ atual educador, em meio a essa era caracterizada pela tecnologia passou a não ser mais considerado o detentor do saber, o oráculo do conhecimento, passando então a ser um personagem tanto importante quanto outrora, mas com certas características que o aperfeiçoa como um sujeito responsável por elucidar os melhores caminhos a serem seguidos pelos seus educandos. Ele deve então incorporar- se como um mediador dessa construção do saber coletivo que ocorre dentro da escola e fora dela. E o momento para que haja esse reconhecimento é verificado no Estágio Supervisionado, já que será 
oportunizado ao estagiário vivenciar os diferentes espaços dinâmicos dentro da instituição escolar.

\section{A FORMAÇÃO DO PROFESSOR NUMA PERSPECTIVA REFLEXIVA}

Não é um assunto que pode deixar passar por despercebido aos olhos de quem está envolvido com a educação. Demo (2004), ao tratar sobre o futuro do professor na Universidade identifica que a formação inicial determina se haverá o rompimento das práticas de reprodução ou não. E ainda acrescenta que a academia que apenas reproduz conhecimentos é desnecessária sua existência, enquanto instituição formadora. Sendo assim é importante perceber a necessidade de rompimentos de muitos paradigmas a outrora incorporados no e pelo meio social. Logo, o que almeja- se na educação é a reconstrução sistemática dos saberes quantas vezes forem necessárias.

E não obstante é na elaboração desses novos e construtivos saberes que pauta- se a construção da autonomia docente como aponta Nóvoa (2009), à medida que assim o professor torna seu cotidiano fonte de investigação, buscando dessa forma elementos que corroborem para ambos os sujeitos (educadores e educandos).

Nos momentos de estágios nas escolas já citadas, buscou-se mesmo diante as limitações que eram visivelmente observadas "dar" aulas que superassem as expectativas dos alunos. Buscando exemplos locais, do seu cotidiano e correlacionando a muito chamada Geografia "chata".

Demo (2004) é muito feliz ao dizer que precisa-se de uma academia que deixe de reproduzir um discurso ultrapassado e nada instigador de obtê-lo- ló. É preciso que se rompa com as práticas conservadoras e por em prática um novo discurso, uma nova filosofia determinada a mudar não só os paradigmas que já não surtem mais efeito, mas também cogitar a necessidade de dinamização dentro do próprio pensamento. É importante que se conheça o passado para entender o presente e ousar prever possíveis fenômenos futuros.

E quando se trata da reflexão dos conteúdos, verifica-se que é importante a participação do educador pois será ele o instrutor direcionando assim os possíveis caminhos a serem trilhado pelo alunado. Para isso, Máciel (2004), aponta que em muitos casos, o educador por não ter tido uma orientação necessária para tornar-se um 
professor reflexivo acaba por não contribuir com a construção do conhecimento, pois quando colocado em alguma situação que requeira a reflexão não consegue direcionar os alunos corretamente, Sendo assim, um professor que não foi formado para ser um profissional pesquisador e reflexivo não terá bases conceituais para assim fazer de seus alunos futuros pesquisadores.

\section{CONSIDERAÇÕES FINAIS}

Portanto, verificou-se que o estágio na formação docente desempenha um papel muito importante na construção do conhecimento. As atividades desenvolvidas nesse período subsidiarão a vida profissional do sujeito enquanto profissional, ou seja, que dará suporte a construção do conhecimento, possibilitando um maior desempenho das funções que lhes são destinadas cada vez mais satisfatoriamente.

Logo, o estágio deve ser visto como um importante componente curricular na formação profissional, contribuindo assim efetivamente na construção de diferentes metodologias. Salienta-se também que, esse momento servirá para que o estagiário identifique-se ou não pela profissão, além de ser um momento de grande importância para o despertar da pesquisa e ação. Assim, aponta-se a necessidade de reflexões constantes a respeito das questões que envolvem o processo de ensino e aprendizagem, deixando de lado os métodos tradicionalistas, como apontado no texto ao trazer o termo "Crítico reprodutivista educacional".

\section{REFERÊNCIAS:}

BURIOLLA, Marta A. F. O Estágio Supervisionado. São Paulo: Cortez, 2001.

CASTROGIOVANNI, Antonio Carlos. Et. al.. Ensino da Geografia: Caminhos e Encantos. Porto Alegre: EDIPICRS,2007.

GUERRA, Miriam Darlete Seade. Reflexões sobre um processo vivido em estágio supervisionado: Dos limites às possibilidades, 1995. 
OLIVEIRA, Christian Dennys Monteiro de Sentidos da Geografia Escolar./ Christian Dennys Monteiro de Oliveira. - Fortaleza: Edições UFC, 2009.

NÓVOA, António. Professores: Imagens do Futuro Presente. Editora: Educa. 2009. Oliveira, Christian Dennys Monteiro de. Sentidos da Geografia Escolar. Christian Dennys Monteiro de Oliveira. - Fortaleza: Edições UFC, 2009.

PIMENTA, Selma Garido e LIMA, Maria Socorro Lucena. Estágio e Docência. $2^{\circ}$ Edição. São Paulo, 2004.

PIMENTA, Selma Garrido; LIMA, Maria Socorro Lucena. Estágio diferentes concepções. In:__ Estágio e docência. São Paulo: Cortez, 2004. P. 33.

SANTOS, M. Por uma outra globalização: do pensamento único à consciência universal. Rio de Janeiro; São Paulo: Record, 2000.

SAVIANI, Dermeval. Educação: do senso comum à consciência filosófica. 17. ed. revista. Campinas, São Paulo: Autores Associados, 2007.

SILVA, Ileizi Luciana Fiorelli. A formação de docentes da Educação Infantil e anos iniciais do Ensino Fundamental, em nível médio, no Estado do Paraná. Documento para organização do Curso de Formação de Professores em nível Médio na Escola Pública do Paraná. 2003. 